Cite this: RSC Adv., 2021, 11, 19723

Received 9th January 2021

Accepted 19th May 2021

DOI: $10.1039 / d 1 r a 00189 b$

rsc.li/rsc-advances
Check for updates

\section{One-pot multicomponent green LED photoinduced synthesis of chromeno[4,3-b]chromenes catalyzed by a new nanophotocatalyst histaminium tetrachlorozincate}

\begin{abstract}
Mahbube Jarrahi, (iD ${ }^{a}$ Reza Tayebee, (DD *a Behrooz Maleki ${ }^{\mathrm{a}}$ and Alireza Salimi (D) ${ }^{\mathrm{b}}$
Histaminium tetrachlorozincate nanoparticles are prepared, characterized and applied as an effective and recoverable photocatalyst in the one-pot, green and multi-component synthesis of various chromenes by the reaction of dimedone and/or 1,3-cyclohexanedione, arylaldehyde and 4-hydroxycoumarin in high yields under solventless conditions at ambient temperature. This new catalyst is characterized by FT-IR, $X R D, E D X, N M R, S E M$ and TEM techniques. The incorporation of histaminium ions into the framework of $\mathrm{ZnCl}_{4}{ }^{2-}$ significantly affected the photocatalytic activity of tetrachlorozincate such that good reusability and recyclability are attained. Moreover, reactive species such as ${ }^{\circ} \mathrm{O}_{2}{ }^{-}$and hydroxyl radicals have proved to be active species in the presented photocatalytic reaction. In addition, the hot filtration test confirms enough stability of the photocatalyst and no significant leaching and destruction of the framework in the course of the reaction. The major advantages of the presented methodology include easy work-up, cost effectiveness, nontoxic nature, broad substrate scope, 100\% atom economy, ease of separation, and environment friendly reaction conditions. Finally, the catalyst could be reused many times without significant loss of activity.
\end{abstract}

\section{Introduction}

The development of green and straightforward multicomponent reactions has attracted great deal of attention from the environment point of view. Multi-component reactions combine at least three reagents at the same time in a single pot to generate intended products in a short reaction time with enhanced atom economy. This interesting strategy can serve as a preferred tool, which has gained attention for traditional multi-step reactions and a new extension has emerged in synthetic organic chemistry as well as in biological scaffolds and the drug discovery field. ${ }^{1-4}$ The principal reaction parameters such as temperature, solvents and catalyst amount strongly affect the selectivity, versatility and environmental acceptability of a multi-component reaction.

Photochemical condensation reactions have been first explored in the early $20^{\text {th }}$ century and opened useful strategies in synthetic organic chemistry and extensive efforts are devoted to various effective contributing experimental parameters related to these types of transformations. ${ }^{5-7}$ There is no doubt that light is a nonpolluting source of energy, which motivates

${ }^{a}$ Department of Chemistry, School of Sciences, Hakim Sabzevari University, Sabzevar, 96179-76487, Iran.E-mail: rtayebee@hsu.ac.ir

${ }^{b}$ Department of Chemistry, Faculty of Science, Ferdowsi University of Mashhad, Mashhad, Iran many photochemical reactions and can effectively be considered as a green solution to reach a cleaner life. Therefore, chemists try to redesign the synthetic methods by focusing on visible resources. Visible light has the potential to act as an inexpensive, abundant, renewable, available source of energy, and a non-polluting reagent for chemical synthesis. Therefore, chemists have promoted photochemical reactions as an interesting filed in organic synthesis. ${ }^{8-10}$ Among many advantages of photochemical reactions, traditional UV light sources have significant drawbacks including various technical complications, energy intensive nature, limited lifetime and considerable requirements due to dissipation of heat generated from the light source. In addition, the energy of a UV photon is generally in the range of carbon-carbon $\sigma$ bonds, which induces problematic complications and may result in various unwanted photo induced decomposition reactions and the generation of obscure optical polymeric materials on the reactor wall. ${ }^{11,12}$ However, most of these drawbacks can be solved by new modifications in reactor design and applying efficient LED lights. ${ }^{13}$

On the other hand, one fundamental impediment that limits the development of photochemical processes is that most organic molecules cannot absorb visible light. This issue limited the application of photochemical reactions and motivated the development of new effective visible light photocatalysts in chemical transformations. ${ }^{14}$ Commonly the applied 
visible-light driven photocatalysts have been classified into two main families of organic and inorganic photosensitive materials. Organic visible light driven photocatalysts (sensitizers) are commonly organic compounds, which involve aromatic rings or conjugated unsaturated bonds that hold the irradiation energy with the help of quantum vibrations. ${ }^{15}$ To achieve effective photocatalysts applicable in the visible spectrum of electromagnetic radiation, they should be colored and should consist of common metal-free organic dyes, whereas the most representative class of inorganic visible-light photocatalysts basically involve metal oxide semiconductors, coordination complexes and some colored metal-organic frameworks. ${ }^{16}$

Chromene derivatives are essential oxygenated heterocyclic compounds that have emerged as important ingredients of many biological active materials in drug chemistry and pharmacology. ${ }^{17-19}$ Chromenes exist in various flavonoids, tocopherols and alkaloids, which exhibit diverse biological, ${ }^{20}$ anticancer, ${ }^{21}$ anti-HIV, ${ }^{22}$ antialzheimer, ${ }^{23}$ anti-tumor, ${ }^{24}$ anti-bacterial, ${ }^{25}$ anti-viral, ${ }^{26}$ anti-leishmanial, ${ }^{27}$ anticoagulant, ${ }^{28}$ antitubercular, ${ }^{29}$ anti-inflammatory, ${ }^{30}$ and anti-tubulin activities. ${ }^{31}$ In addition, chromenes can activate the potassium channels and may prohibit some reductases and some phosphodiesterases and these compounds have been utilized as cosmetics, pigments, biodegradable agrochemicals, colored optical lasers, brighteners, and fluorescence biomarkers. ${ }^{32-34}$ There are many reports to synthesize varieties of chromeno[4,3- $b]$ chromenes by the reaction of different arylaldehydes with 1,3-dicarbonyls and 4-hydroxycoumarin in the presence of various catalysts such as $\mathrm{Ni}(\mathrm{II})$-bis(oxazoline), ${ }^{35} \mathrm{Fe}_{3} \mathrm{O}_{4} @ \mathrm{SiO}_{2}$-sultone, ${ }^{36} \mathrm{WO}_{3} / \mathrm{ZnO} @ \mathrm{NH}_{2}{ }^{-}$ $\mathrm{EY},{ }^{37}$ and $\mathrm{Zn}$ (L-proline) $2 .{ }^{38}$ Although most of these protocols are effective, some of them have some disadvantages such as side reactions, lengthy reaction time, tedious workup, high reaction temperature, moderate yields and non-reusable mediators. Therefore, development of novel synthetic green procedures is of great interest in synthetic organic chemistry because of environmental and economic concerns.

As photoredox catalysis obeys the general property of an excited state that is both more easily reducible and oxidizable than its corresponding ground states, herein and in continuation of our previous reports on the green multi-component synthesis of heterocycles, ${ }^{39-42}$ we report our findings on using histaminium tetrachlorozincate as an effective and recoverable catalyst in the green, one-pot and multi-component synthesis of various chromene derivatives via the multi-component condensation of aromatic aldehydes with a suitable 1,3-diketone and 4-hydroxycoumarin under solventless condition at ambient temperature (Scheme 1). Herein, the used photocatalyst can serve either as an electron-donor or acceptor in the catalytic route. The photoreactivity property originates from the nature of the oxidized metal center and the reduced ligand.

\section{Experimental section}

\subsection{Materials and methods}

Solvents and all materials were purchased from commercial resources and utilized as received without any further purification. Histamine dihydrochloride (Sigma-Aldrich, >99\%), aromatic aldehydes (Merck, Fluka and Sigma-Aldrich, 98-99\%), dimedone (Sigma-Aldrich, >97\%), 4-hydroxycoumarin (Fluka, purum), and acetonitrile (Sigma-Aldrich, 99.8\%) were used as received. The performed LEDs were commercial and no cutoff filter was used. Fourier transform infrared (FT-IR) spectra were recorded on a Shimadzu 8700 Fourier transform spectrophotometer in the range 400 to $4000 \mathrm{~cm}^{-1}$ with $\mathrm{KBr}$ pellets. UVvisible spectra were recorded on a Photonix UV-visible array spectrophotometer. X-ray diffraction (XRD) patterns were acquired on a PHILIPS PW 1730 diffractometer with $\mathrm{Cu} \mathrm{K}_{\alpha}$ at 30 $\mathrm{mA}, 40 \mathrm{keV}$ and a scanning rate of $3^{\circ} \mathrm{min}^{-1}$ in the $2 \theta$ domain from 5 to $80^{\circ}$. Energy dispersive X-ray spectroscopy (EDS) was performed with an Electron Probe Microanalyser JEOL JXA-8230 equipped with an energy dispersive spectrometer Bruker QUANTAX 200. A Mira 3-MU field emission scanning electron microscope (FESEM) was used to investigate the morphology of the synthesized nanomaterials. Particle size and further morphology studies were performed on a TEM (Philips CM-200 and Titan Krios). NMR experiments were carried out on a Bruker Avance DMX600 instrument operating at $400 \mathrm{MHz}$ for proton.

\subsection{Synthesis of histaminium tetrachlorozincate}

Pure histaminium zinctetrachloride was prepared under solvothermal conditions by mixing of histamine dihydrochloride

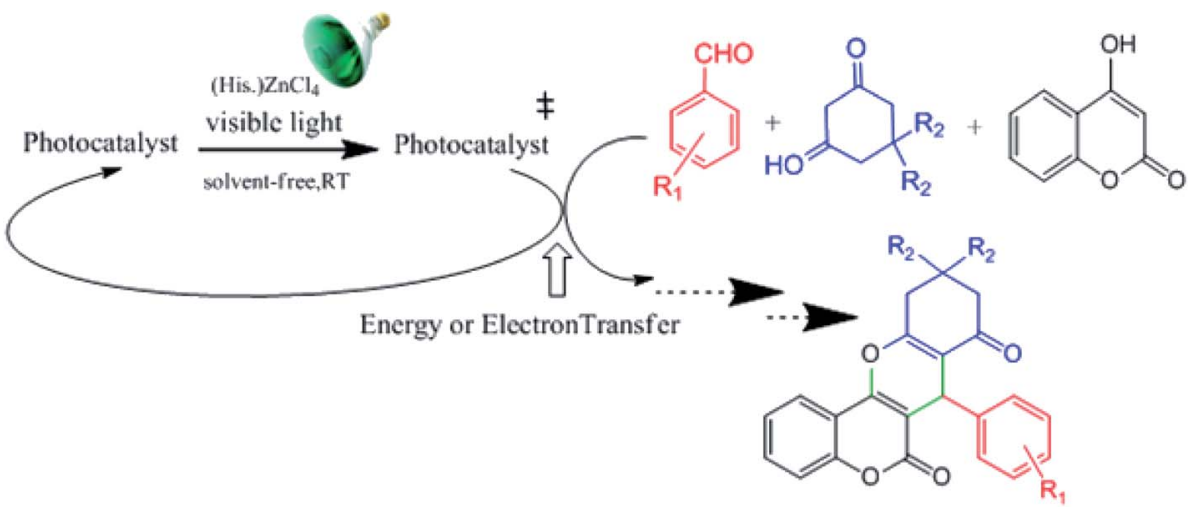

Scheme 1 The general route describing the desired photocatalytic condensation reaction by the mediation of histaminium tetrachlorozincate as a photocatalyst. 
(0.21 g, $1.1 \mathrm{mmol})$ with $\mathrm{ZnCl}_{2}(0.06 \mathrm{~g}, 0.05 \mathrm{mmol})$ in warm methanol $\left(65^{\circ} \mathrm{C}, 13 \mathrm{~mL}\right)$. After mixing, the mixture was kept at room temperature for $24 \mathrm{~h}$ without disturbance. Finally, the resulting white precipitate was isolated, washed with deionized water and dried in air at $70{ }^{\circ} \mathrm{C}$.

\subsection{General route for the synthesis of chromeno[4,3-b]} chromenes

To a $25 \mathrm{~mL}$ flask container, histaminium tetrachlorozincate (2 $\mathrm{mg}$ ), benzaldehyde (100 mg, $1 \mathrm{mmol}$ ), dimedone (140 mg, 1 $\mathrm{mmol}$ ) and 4-hydroxycoumarin (162 mg, $1 \mathrm{mmol}$ ) were added. In the case of reactions with the solvent, acetonitrile $(3 \mathrm{~mL})$ was
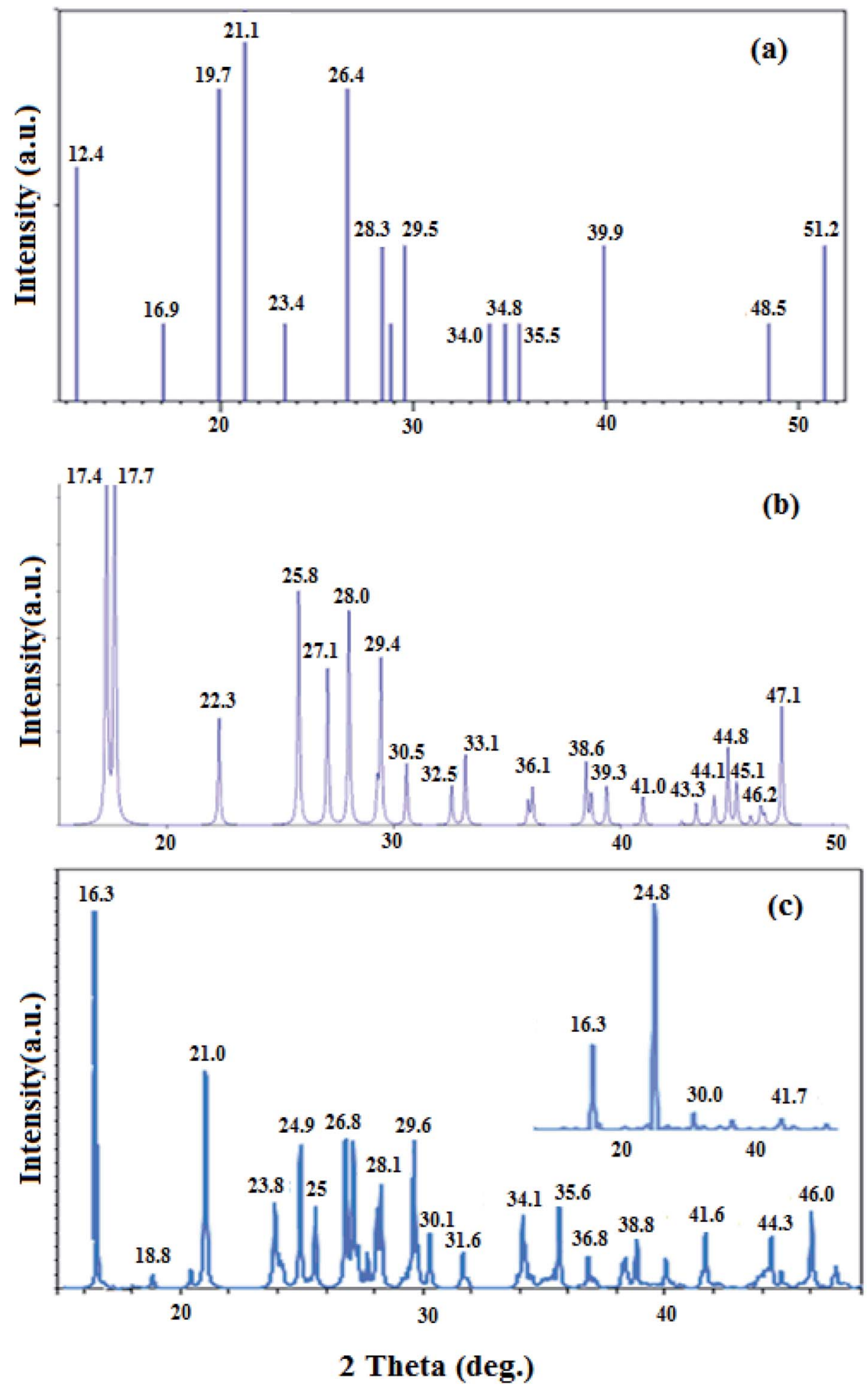

Fig. 1 XRD patterns of histamine (a), tetrachlorozincate anion (b) and histaminium tetrachlorozincate (c). 
used. Then, the mixture was irradiated with a visible green lightemitting diode (LED) at room temperature in an open air condition. Production of the desired chromene was monitored by TLC and after completion of the reaction, the reaction mixture was quenched with $\mathrm{H}_{2} \mathrm{O}(3 \mathrm{~mL})$ and the remained precipitate was dissolved in EtOAc. Then, the ethyl acetate layer was removed and the aqueous phase was extracted with ethyl acetate $(3 \times 3 \mathrm{~mL})$. Finally, the combined organic layer was dried on $\mathrm{Na}_{2} \mathrm{SO}_{4}$ and concentrated in a vacuum. The crude product could be further purified through column chromatography (100-200 mesh silica gel; EtOAc/hexane) to obtain the pure products.

\section{Results and discussion}

\subsection{Physicochemical properties and characterization of histaminium tetrachlorozincate}

Histamine (2-aminoethylimidazole) is a familiar, biocompatible and pharmacologically important material which can be suitable as a good ligand due to its unique characteristics under in vivo conditions and readily binds to several metal ions such as nickel(II), cobalt(II), zinc(II) and copper(II) to form complexes with moderate stability. Histamine free base involves an imidazole ring with an aminoethyl side-chain, which accepts a proton to give a histaminium dication. The chemical structure and morphology of the histaminium tetrachlorozincate photocatalyst were explored by means of SEM, EDX, FT-IR, NMR and XRD. FT-IR is used as the most informative technique to determine the surface interactions in the nanomaterial. Moreover, powder X-ray diffraction (XRD) can confirm the formation of the histaminium tetrachlorozincate framework. The morphology and particle size of histaminium tetrachlorozincate were further confirmed by TEM, SEM and EDX analyses. The

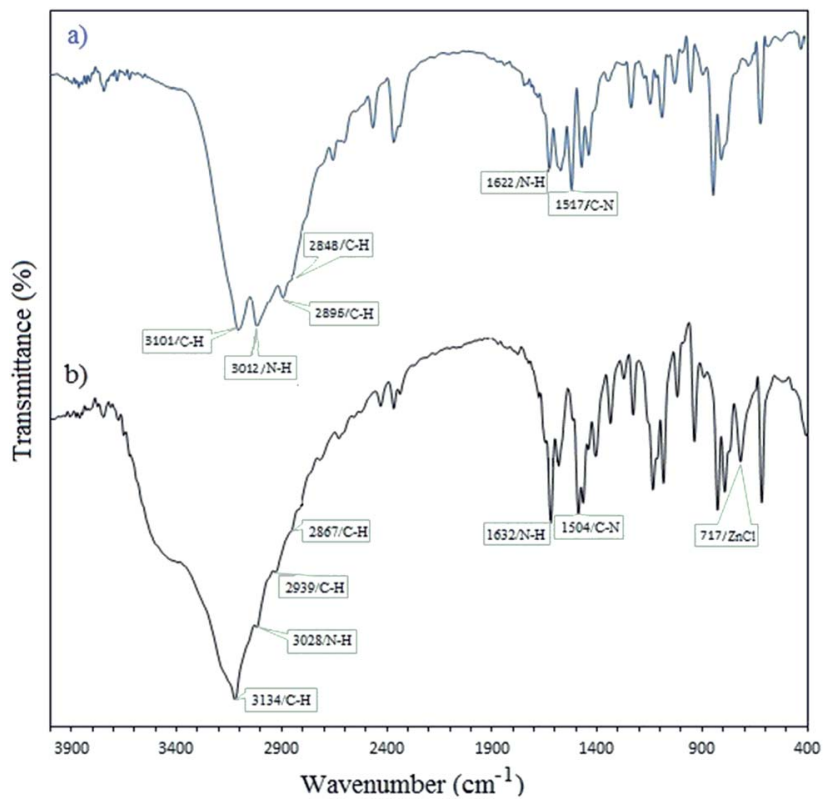

Fig. 2 FT-IR spectra of (a) histamine and (b) histaminium tetrachlorozincate. latter clearly indicated that the material was pure and no impurity peaks were observed.

3.1.1 XRD analysis. The wide-angle XRD patterns of histamine (a), tetrachlorozincate (b) and histaminium tetrachlorozincate (c) are shown in Fig. 1. Free histamine exhibited several peaks at the $2 \theta$ of $12.4,16.9,19.7,21.1,23.4,26.4,28.3$, 29.5, 34.0, 34.8, 35.5, 39.9, 48.5 and $51.2^{\circ}$ (Fig. 1a). In addition, anionic tetrachlorozincate revealed many peaks at $17.4,17.7$, 22.3, 25.8, 27.1 , 28.0, 29.4, 30.5, 32.5, 33.1, 36.1, 38.6, 39.3, 41.0,
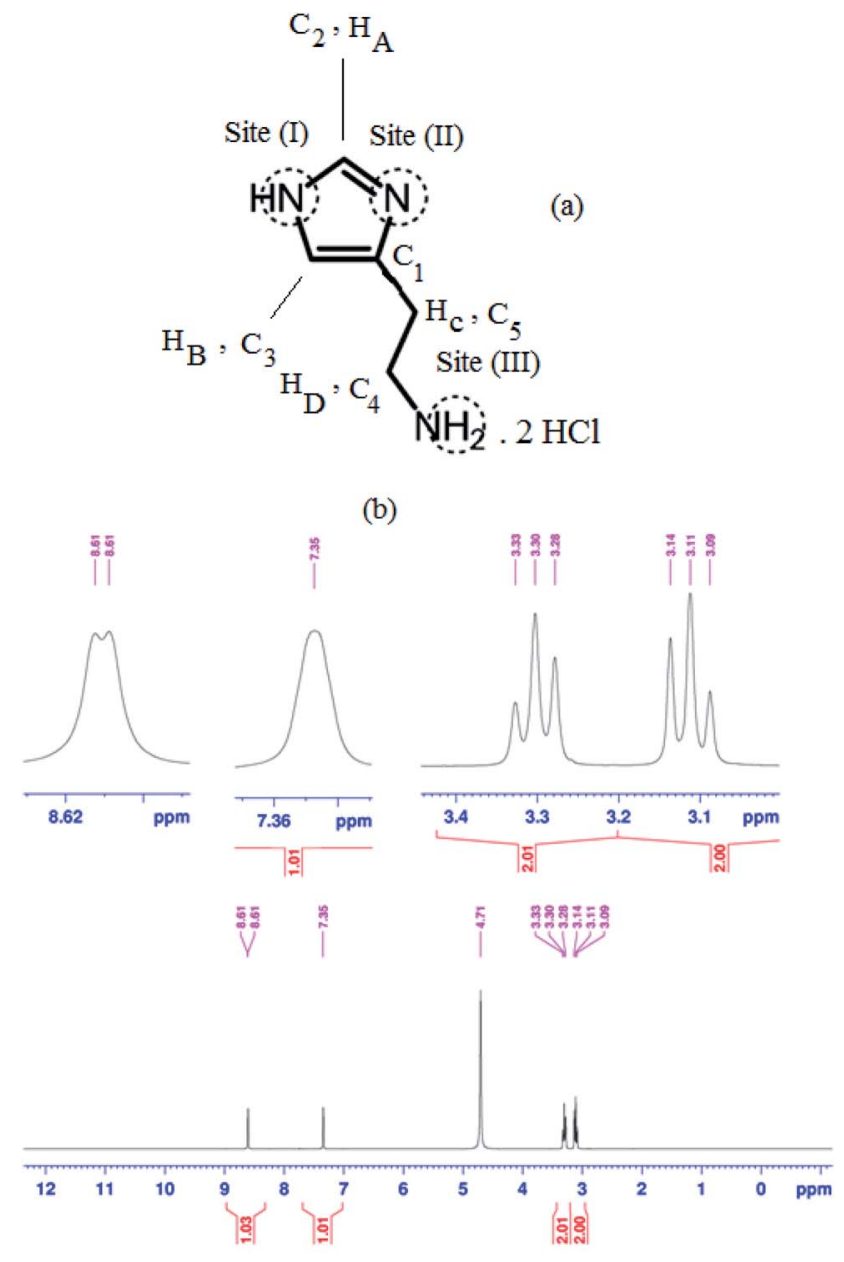

(c)

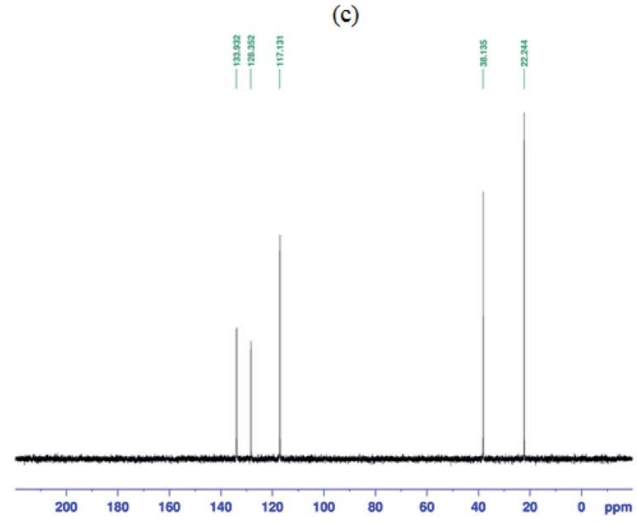

Fig. 3 Schematic representation of histamine (a) and ${ }^{1} \mathrm{H}$ NMR (b) and ${ }^{13} \mathrm{C}$ NMR (c) spectra of histaminium tetrachlorozincate. 


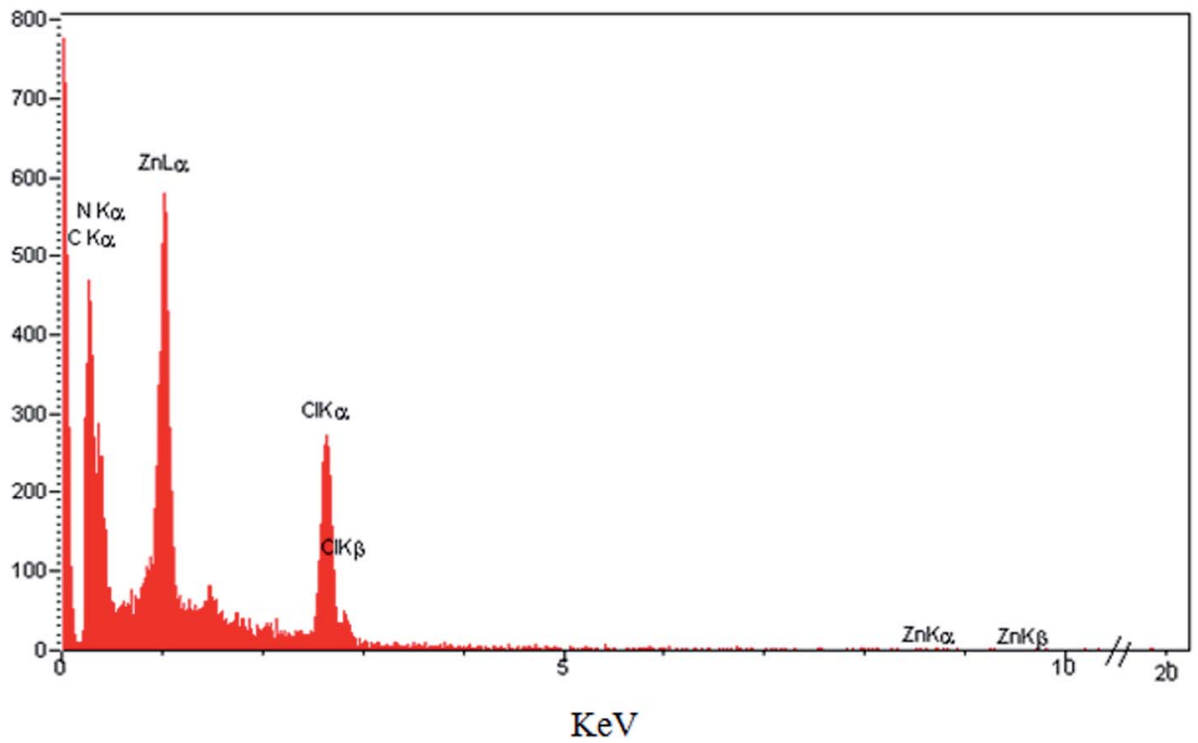

Fig. 4 EDS pattern of histaminium tetrachlorozincate.

43.3, 44.1, 44.8, 45.1, 46.2 and $47.1^{\circ}$ (Fig. 1b). Eventually, the target composite nanomaterial showed the main peaks at the $2 \theta$ values of $16.5,17.3,18.8,21.0,23.8,24.9,25.0,26.8,28.1,29.6$, 30.2 , 31.6, 34.1, 35.6, 36.8, 38.8, 41.6, 44.3 and $46.0^{\circ}$ (Fig. 1c). Repeating XRD of this material under lower magnification showed the main peaks of $16.3,24.8,30.0$ and $41.7^{\circ}$ (inset of Fig. 1c). Comparison of these XRD patterns showed that the XRD of the new nanocomposite is mainly similar to that of tetrachlorozincate and histaminium ions had no significant effect on the crystal structure of anionic $\mathrm{ZnCl}_{4}{ }^{2-}$. In addition, the average crystallite size of histaminium tetrachlorozincate is estimated by the use of Debye-Scherrer's equation (eqn (1)).

$$
L=0.98 \lambda / \beta \cos \theta
$$

where $\beta$ is the excess width-line at the half-maximum of the diffraction peak in radians, $\theta$ is the Bragg angle in degrees, and $\lambda$ is the wavelength. By calculation, an average crystallite size of about $24 \mathrm{~nm}$ was attained for this nanophotocatalyst.

3.1.2 FT-IR spectroscopy. FT-IR spectroscopy was used to define the structure of the synthesized catalyst. As shown in Fig. 2a, the peak at $3101 \mathrm{~cm}^{-1}$ is assigned to the $\mathrm{C}-\mathrm{H}$ stretching of the imidazole ring in the histamine fragment. Secondary amine $\mathrm{N}-\mathrm{H}$ stretching mode was observed at $3012 \mathrm{~cm}^{-1}$. The

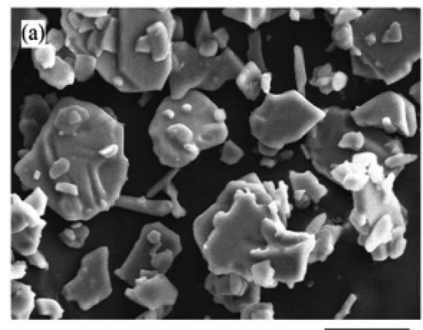

$\overline{100 \mathrm{~nm}}$

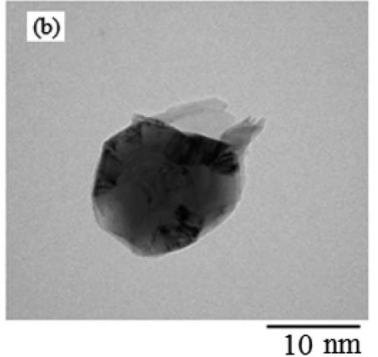

Fig. 5 SEM (a) and TEM (b) images of histaminium tetrachlorozincate.
C-H stretching of the alkyl group was detected by the peaks at 2895 and $2848 \mathrm{~cm}^{-1}$. The bands at 1622 and $1517 \mathrm{~cm}^{-1}$ are due to the $\mathrm{N}-\mathrm{H}$ bending and $\mathrm{C}-\mathrm{N}$ stretching vibrations of the imidazole ring, respectively. ${ }^{43}$ The FT-IR spectrum of histaminium tetrachlorozincate (Fig. 2b) is not significantly different from that of histamine and only the peak at $717 \mathrm{~cm}^{-1}$ confirmed the incorporation of zinc into the material, which is related to $\mathrm{Zn}-\mathrm{Cl}$ stretching.

3.1.3 NMR spectroscopy. There are three sites in histamine dihydrochloride, which can act as proton donating/accepting
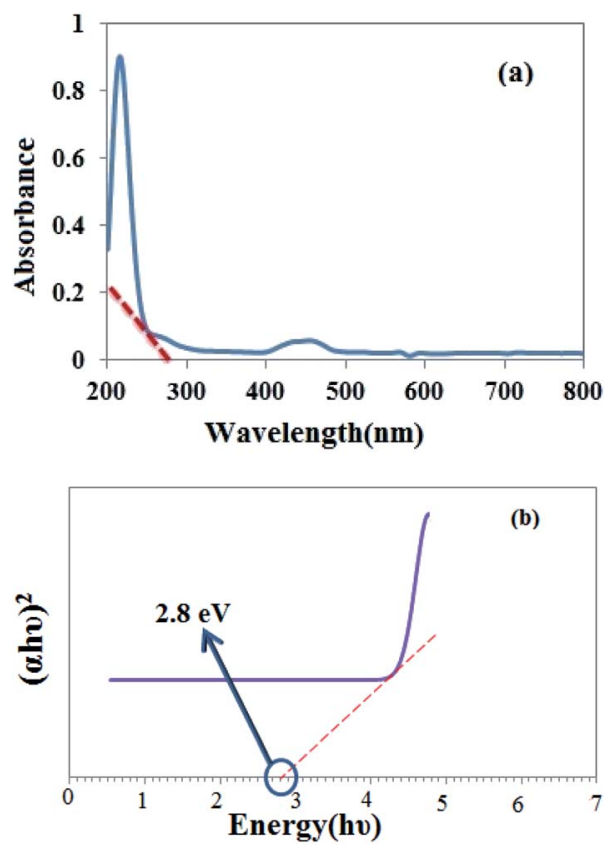

Fig. 6 (a) UV-Vis absorption spectrum and (b) the corresponding Tauc plot of histaminium tetrachlorozincate. 
Table 1 Optimization of the light source in the condensation reaction $^{a}$

\begin{tabular}{lllll}
\hline Entry & Light source & Light specification & Time (h) & Yield $^{b}(\%)$ \\
\hline 1 & Dark & - & 3 & Trace \\
2 & White LED & $2.5 \mathrm{~W}$ & 3 & 24 \\
3 & Green & $2.5 \mathrm{~W}, \lambda_{\max }=535 \mathrm{~nm}$ & 3 & 57 \\
4 & Blue & $2.5 \mathrm{~W}, \lambda_{\max }=431 \mathrm{~nm}$ & 3 & 46 \\
5 & Red & $2.5 \mathrm{~W}, \lambda_{\max }=695 \mathrm{~nm}$ & 3 & 43 \\
6 & Violet & $2.5 \mathrm{~W}, \lambda_{\max }=455 \mathrm{~nm}$ & 3 & 42
\end{tabular}

${ }^{a}$ Reaction conditions: benzaldehyde $(1 \mathrm{mmol})$, dimedone $(1 \mathrm{mmol})$, and 4-hydroxycoumarin $(1 \mathrm{mmol})$ with the photocatalyst $(1 \mathrm{mg})$ under an open atmosphere at RT in $3 \mathrm{~mL}$ acetonitrile. ${ }^{b}$ Yields refer to the isolated product in all cases.

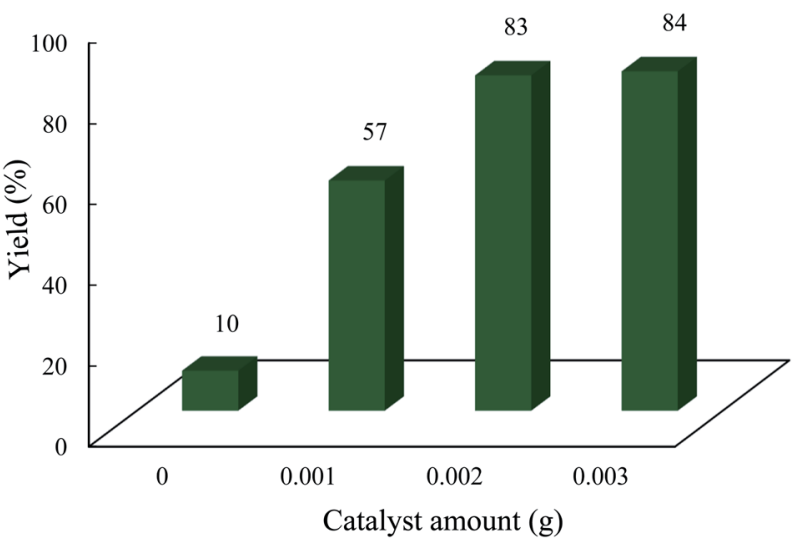

Fig. 7 Effect of catalyst amount on the condensation reaction. The reaction conditions are described in Table 1 . The reaction time was $3 \mathrm{~h}$ under solvent conditions (acetonitrile, $3 \mathrm{~mL}$ ).

centers (Fig. 3a). The ${ }^{1} \mathrm{H}$ NMR spectrum of histamine in $\mathrm{CDC}_{3}$ shows peaks at $3.21\left(2 \mathrm{H}, \mathrm{t}, \mathrm{CH}_{2}\right), 3.39\left(2 \mathrm{H}, \mathrm{t}, \mathrm{CH}_{2}\right), 7.43(1 \mathrm{H}, \mathrm{s}$, ring $\mathrm{CH})$, and $8.70(1 \mathrm{H}, \mathrm{d}$, ring $\mathrm{CH}){ }^{44}$ The ${ }^{13} \mathrm{C}$ NMR of this compound also shows 5 peaks at $30.40\left(\mathrm{C}_{5}\right), 41.73\left(\mathrm{C}_{4}\right), 118.00$

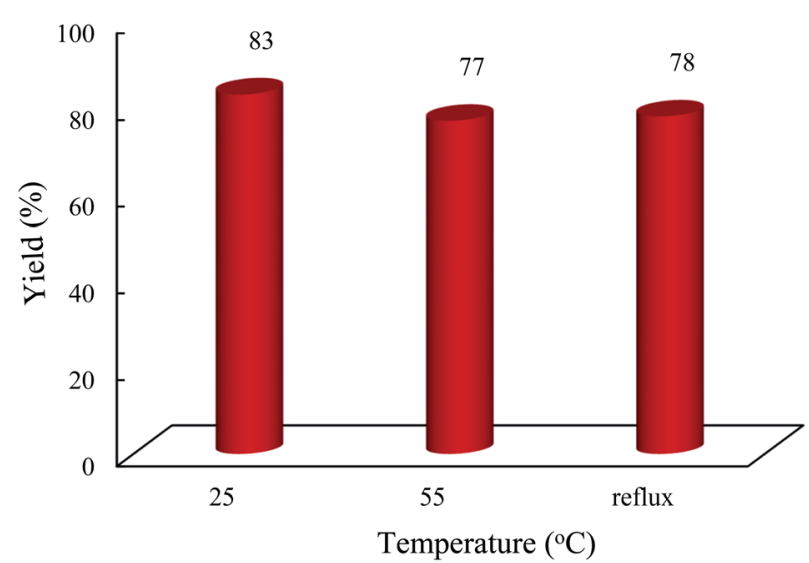

Fig. 8 Impact of temperature on the condensation reaction. The reaction conditions are described in Table 1 . The reaction time was $3 \mathrm{~h}$ and $0.002 \mathrm{~g}$ of photocatalyst was used under solvent conditions (acetonitrile, $3 \mathrm{~mL}$ ).
$\left(\mathrm{C}_{3}\right), 134.64\left(\mathrm{C}_{2}\right)$ and $134.96\left(\mathrm{C}_{1}\right)$. The ${ }^{1} \mathrm{H}$ NMR spectrum of histaminium tetrachlorozincate in $\mathrm{D}_{2} \mathrm{O}$ also revealed comparable peaks at $3.11\left(2 \mathrm{H}, \mathrm{t}, \mathrm{CH}_{2}\right), 3.30\left(2 \mathrm{H}, \mathrm{t}, \mathrm{CH}_{2}\right), 7.35(1 \mathrm{H}, \mathrm{s}$, ring $\mathrm{CH})$, and $8.61(1 \mathrm{H}, \mathrm{d}$, ring $\mathrm{CH})$ (Fig. $3 \mathrm{~b})$. The small up-field shift would be due to metal coordination. The ${ }^{13} \mathrm{C}$ NMR of this compound also exhibited 5 peaks at $22.24\left(\mathrm{C}_{5}\right), 38.13\left(\mathrm{C}_{4}\right)$, $117.13\left(\mathrm{C}_{3}\right), 128.35\left(\mathrm{C}_{2}\right)$ and $133.93\left(\mathrm{C}_{1}\right)$ (Fig. 3c). The little linebroadening would be due to a slow internal fluctuation with a timescale close to the NMR frequency. ${ }^{45}$

3.1.4 SEM/EDS analysis. Scanning electron micrography and energy dispersive X-ray spectroscopy were used as beneficial methods to determine the morphology and chemistry of the individual particles and bulk materials (Fig. 4 and 5). EDS analysis clarified the included elements and brought a quantitative assessment of each element. This study confirmed the atomic concentration \% of carbon (44.7), nitrogen (16.6), chlorine (29.3) and zinc (7.9) as the main elements of histaminium tetrachlorozincate and the molecular formula of $\mathrm{C}_{5} \mathrm{H}_{11} \mathrm{Cl}_{4} \mathrm{~N}_{3} \mathrm{Zn}$ was recommended. In addition, the SEM image of this photocatalyst showed that the particles have an angular tile-shape with a wide range of sizes (Fig. 5a). The TEM image of histaminium tetrachlorozincate revealed a mean particle size of about $15-30 \mathrm{~nm}$ in most cases, which is in good agreement with XRD results (Fig. $5 b$ ).

3.1.5 UV-visible spectroscopy. The UV-Vis absorption spectrum of the photocatalyst was analyzed in order to investigate the viable mechanism involved in the effective visible light absorption. The UV-Vis absorption spectrum of histaminium tetrachlorozincate in the region of 200-300 nm (Fig. 6a) provided the band-gap edge, which may be ascribed to the photo-excitation occurring from the valence band to the conduction band. The optical band-gap of this sample was estimated using the Tauc plot based on the extrapolation of the linear slope to photon energy. The calculated band-gap energy of histaminium tetrachlorozincate was found to be $2.8 \mathrm{eV}$. The extrapolation plot of $h v v s$. $(\alpha h v)^{2}$ was applied to get the optical energy band-gap $\left(E_{\mathrm{g}}\right)$ as shown in Fig. 6b. In this relation, the analysis is performed based on the equation $\alpha h v=A\left(h v-E_{\mathrm{g}}\right) n$, where $\alpha, h v, E_{g}$, and $A$ refer to the absorption coefficient, light frequency, band-gap, and a constant, respectively. ${ }^{46}$

\subsection{Catalytic tests}

3.2.1 Impact of the light source on the catalytic condensation reaction. In order to derive the best conditions, a model reaction was conducted using benzaldehyde $(1 \mathrm{mmol})$, dimedone $(1 \mathrm{mmol})$, and 4-hydroxycoumarin $(1 \mathrm{mmol})$ with the photocatalyst $(0.001 \mathrm{~g})$ under solvent conditions (acetonitrile, 3 $\mathrm{mL})$ against irradiation with a green $\operatorname{LED}\left(\lambda_{\max }=535 \mathrm{~nm}\right)$ (Table 1). The reaction mixture was set at room temperature in an open air test tube equipped with a magnet. The desired product chromeno[4,3-b]chromene was formed in good yield after $3 \mathrm{~h}$. This experiment demonstrated that if we perform the reaction under the dark conditions, only a trace amount of the product would be obtained under the same conditions. In addition, a green LED was effective and resulted in 57\% yield. Moreover, this condensation reaction was really a photocatalytic one 


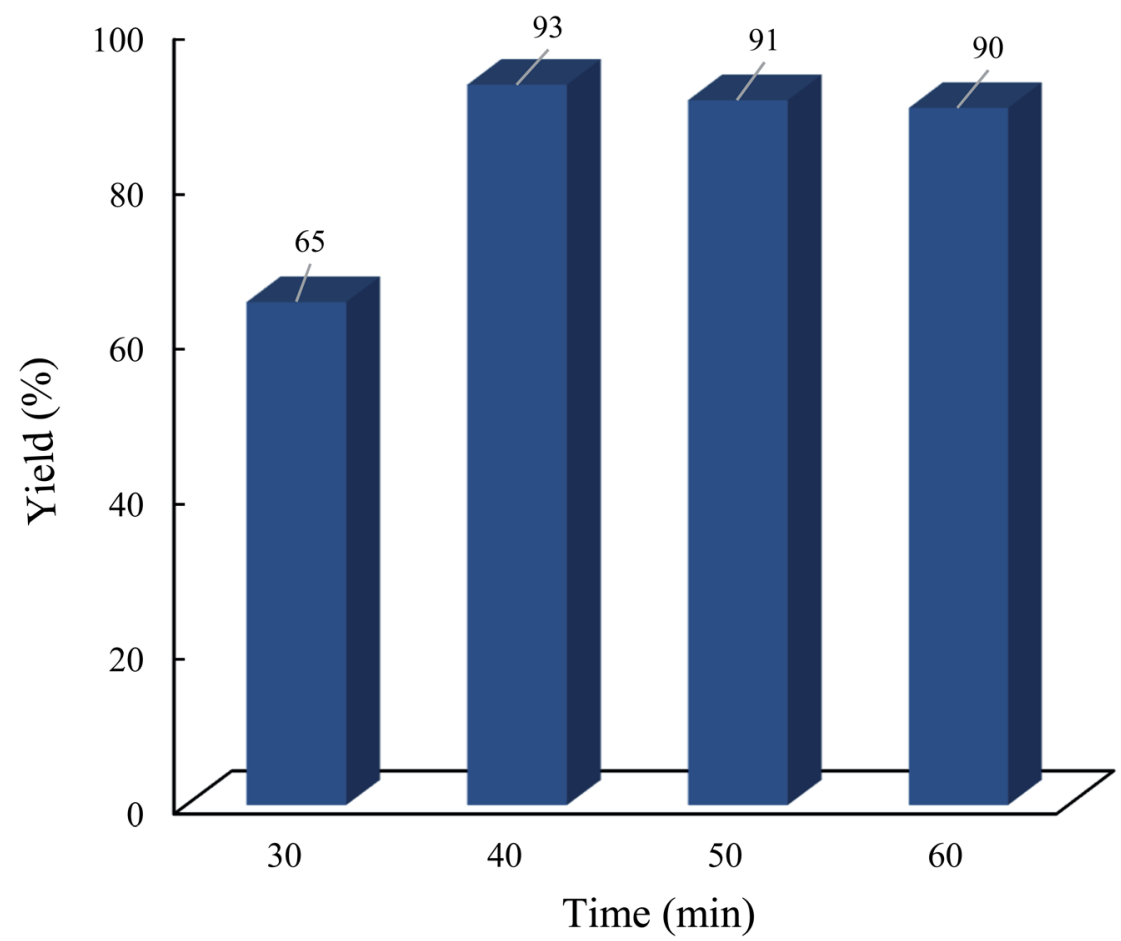

Fig. 9 Effect of time on the reaction progress. Benzaldehyde $(1 \mathrm{mmol})$, dimedone $(1 \mathrm{mmol})$, and 4-hydroxycoumarin (1 mmol) were reacted in the presence of the photocatalyst $(2 \mathrm{mg})$ under an open atmosphere at room temperature with a green LED in the absence of a solvent.

Table 2 Comparison of the catalytic activity of histaminium tetrachlorozincate with some reported catalysts in the synthesis of chromeno[4,3-b] chromene ${ }^{a}$

\begin{tabular}{|c|c|c|c|c|c|}
\hline Catalyst & Time (h) & Temp $\left({ }^{\circ} \mathrm{C}\right)$ & Solvent & Yield (\%) & Ref. \\
\hline Eozin Y $(2 \mathrm{~mol} \%)$ & 3.5 & r.t. & $\mathrm{CH}_{3} \mathrm{CN}$ & 77 & 47 \\
\hline $\mathrm{Fe}(\mathrm{DS})_{3}(10 \mathrm{~mol} \%)$ & 2 & 70 & $\mathrm{H}_{2} \mathrm{O}$ & 87 & 49 \\
\hline $\mathrm{CuFe}_{2} \mathrm{O}_{4} @ \mathrm{SO}_{3} \mathrm{H}(0.05 \mathrm{~g})$ & 2.5 & 70 & EtOH & 90 & 50 \\
\hline $\mathrm{Fe}_{3} \mathrm{O}_{4} @ \mathrm{SiO}_{2} @\left(\mathrm{CH}_{2}\right)_{3} \mathrm{OMoO}_{3} \mathrm{H}(2 \mathrm{mg})$ & $45 \mathrm{~min}$ & 80 & - & 90 & 51 \\
\hline
\end{tabular}

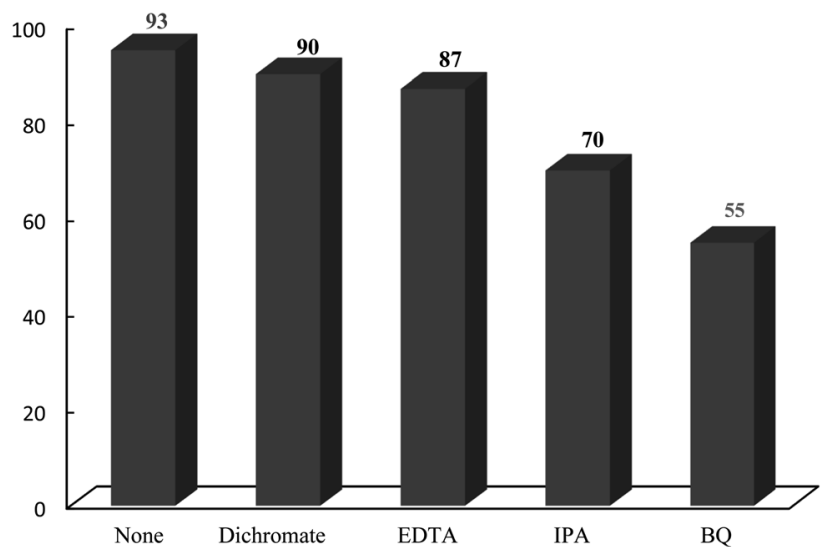

Fig. 10 Effect of some familiar scavengers on the reaction progress under the standard reaction conditions (benzaldehyde $(1 \mathrm{mmol}$ ), dimedone $(1 \mathrm{mmol})$, and 4 -hydroxycoumarin $(1 \mathrm{mmol})$ were reacted in the presence of the photocatalyst $(2 \mathrm{mg}$ ) under an open atmosphere at room temperature with a green LED under solvent-free conditions after $40 \mathrm{~min}$ ). In all cases $1 \times 10^{3-} \mathrm{M}$ solution of the scavenger is used. because of the trace yield obtained under the dark conditions. Table 1 also shows that a green $\operatorname{LED}\left(\lambda_{\max }=535 \mathrm{~nm}\right)$ achieved the best yield in comparison with other colors illuminating at the same power and under similar reaction conditions.

3.2.2 Studying the impact of catalyst amount on the condensation reaction. The condensation reactions were carried out with different amounts of the photocatalyst in order to optimize the exact quantity of the needed photocatalyst under solvent conditions (Fig. 7). It was observed that $0.002 \mathrm{~g}$ of the photocatalyst is appropriate to achieve the best yield of $83 \%$. However, a further increase in the catalyst amount had no clear effect on the yield\% and reaction time.

3.2.3 Role of reaction temperature. To improve the yield and accomplish the best conditions, the effect of temperature was also studied on the selected standard reaction of dimedone, benzaldehyde and 4-hydroxycoumarin (Fig. 8). As shown, yield\% was a little decreased when the temperature increased 
Table 3 Substrate scope for the condensation of dimedone, benzaldehyde, and 4-hydroxycoumarin ${ }^{a}$

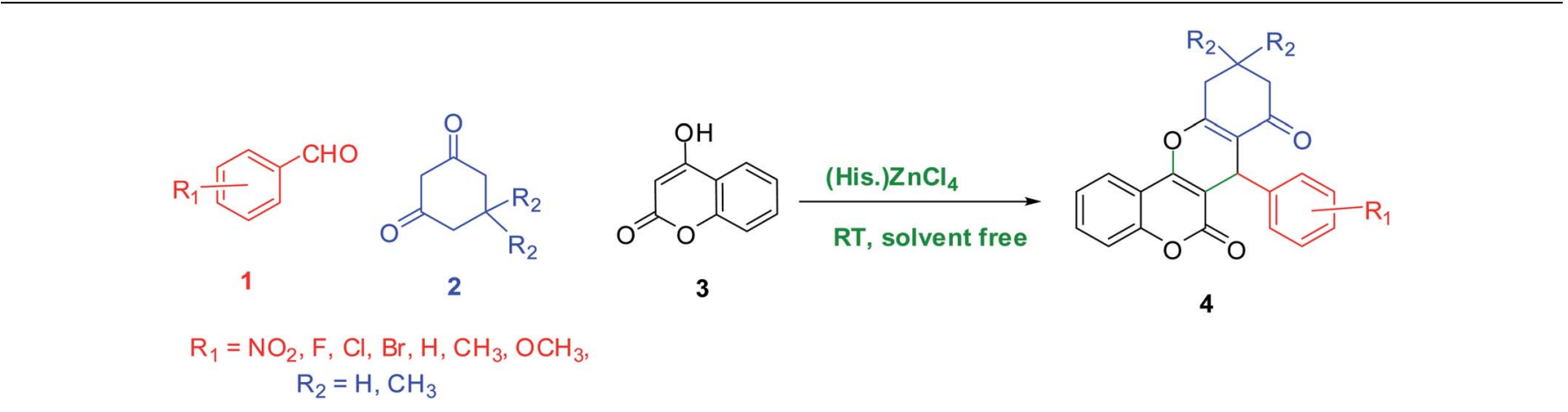

\begin{tabular}{|c|c|c|c|c|c|c|}
\hline \multirow[b]{2}{*}{ Entry } & \multirow[b]{2}{*}{ Benzaldehyde } & \multirow[b]{2}{*}{ Diketone } & \multirow[b]{2}{*}{ Product } & \multirow[b]{2}{*}{ Yield (\%) } & \multicolumn{2}{|l|}{$\mathrm{Mp}$} \\
\hline & & & & & Found & Reported $^{56-58}$ \\
\hline
\end{tabular}

1<smiles>O=Cc1ccc([N+](=O)[O-])cc1</smiles><smiles>O=Cc1ccccc1</smiles>

2

3<smiles>O=Cc1ccc(Br)cc1</smiles>

4<smiles>COc1ccc(C=O)cc1</smiles><smiles>O=Cc1cccc([N+](=O)[O-])c1</smiles><smiles>CC1(C)CC(=O)CC(=O)C1</smiles><smiles>CC1(C)CC(=O)C2=C(C1)Oc1c(c(=O)oc3ccccc13)C2c1ccc([N+](=O)[O-])cc1</smiles><smiles>CC1(C)CC(=O)CC(=O)C1</smiles><smiles>CC1(C)CC(=O)C2=C(C1)Oc1c(c(=O)oc3ccccc13)C2c1ccccc1</smiles>

93

222-224

220-222

73

134-135

133-135

72

187-189

76
219-220 218-220 
<smiles></smiles>

1<smiles>[R]C1(CC)CC(=O)CC(=O)C1</smiles>

2<smiles>O=c1cc(O)c2ccccc2o1</smiles>

3<smiles>[R]c1ccc(C2C3=C(CC([R])([R])CC3=O)Oc3oc4ccccc4c(=O)c32)cc1</smiles>

4

$$
\begin{gathered}
\mathrm{R}_{1}=\mathrm{NO}_{2}, \mathrm{~F}, \mathrm{Cl}, \mathrm{Br}, \mathrm{H}, \mathrm{CH}_{3}, \mathrm{OCH}_{3}, \\
\mathrm{R}_{2}=\mathrm{H}, \mathrm{CH}_{3}
\end{gathered}
$$

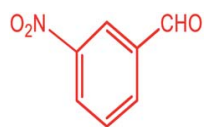

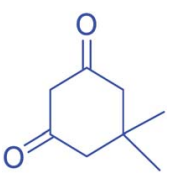

78

Yield (\%)
$\mathrm{Mp}$

Found
$230-232$ from 25 to $55^{\circ} \mathrm{C}$. Also, a further increase of temperature did not alter the yield. Therefore, the temperature of $25^{\circ} \mathrm{C}$ was kept as the best in all runs.

3.2.4 Role of reaction time under solvent-free conditions. The impact of time was also researched to explore the minimum time needed to reach the best yield under solvent-free conditions. It is evident that the photocatalyst had shown good activity because of $65 \%$ yield attained after $30 \mathrm{~min}$. As shown in Fig. 9, 93\% yield was reached after 40 min under the above optimum conditions in the absence of a solvent.

3.2.5 Superiority of the presented protocol over some reported methodologies. As we know, some protocols have been

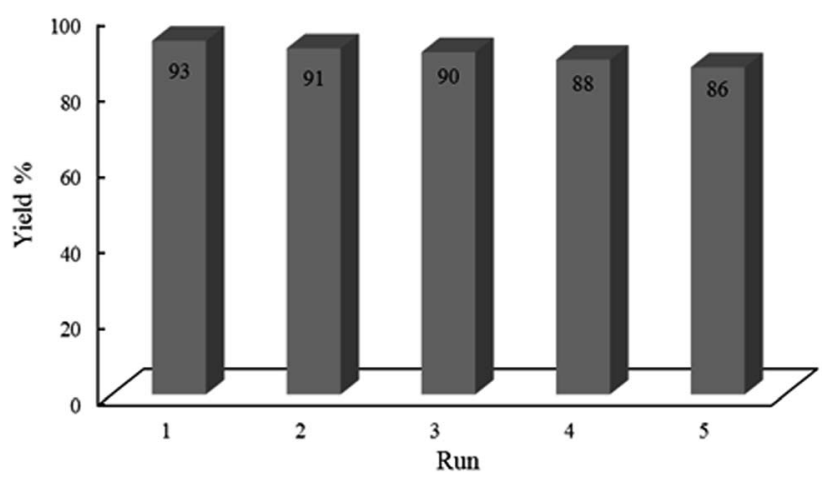

Fig. 11 Yield\% vs. reusability of histaminium tetrachlorozincate. used for the preparation of chromeno[4,3-b]chromenes under different conditions. Herein, the reaction yield of the performed condensation reaction contrasted with those reported (Table 2). Compared to all mentioned catalysts, the presented methodology is a special case that offers a successful route for one-pot single-step synthesis of the intended products under very mild conditions under an open atmosphere at room temperature by means of a green LED irradiation source. The comparison was made based on the catalyst concentration, reaction time and yield $\%$. Clearly, the present report gives rise to a few advantages like using an environmentally benign photocatalyst under ambient reaction conditions to achieve different chromenes.

3.2.6 Active species scavenging experiments. To identify the principal active species involved in the photocatalytic route, a number of scavenging experiments were conducted. $p$-Benzoquinone (BQ) as an $\mathrm{O}_{2}{ }^{--}$scavenger, ${ }^{52}$ dichromate as an $\mathrm{e}^{-}$ scavenger, ${ }^{53}$ EDTA as an $\mathrm{h}^{+}$scavenger, ${ }^{54}$ and isopropyl alcohol (IPA) as a scavenger for the hydroxyl free radicals ${ }^{55}$ were used during the standard photocatalytic reactions. These series of experiments established that all the used scavengers show a significant scavenging power with the order of BQ $>$ IPA > EDTA $>$ potassium dichromate $>$ no scavenger (Fig. 10). However, it seems that the superoxide anion $\left(\mathrm{O}_{2}{ }^{-}\right)$is one of the major involved components because of its crucial role in the photocatalytic process. As a result, the superoxide radical-anion and hydroxyl radical would be the main species involved in the photocatalytic process. 


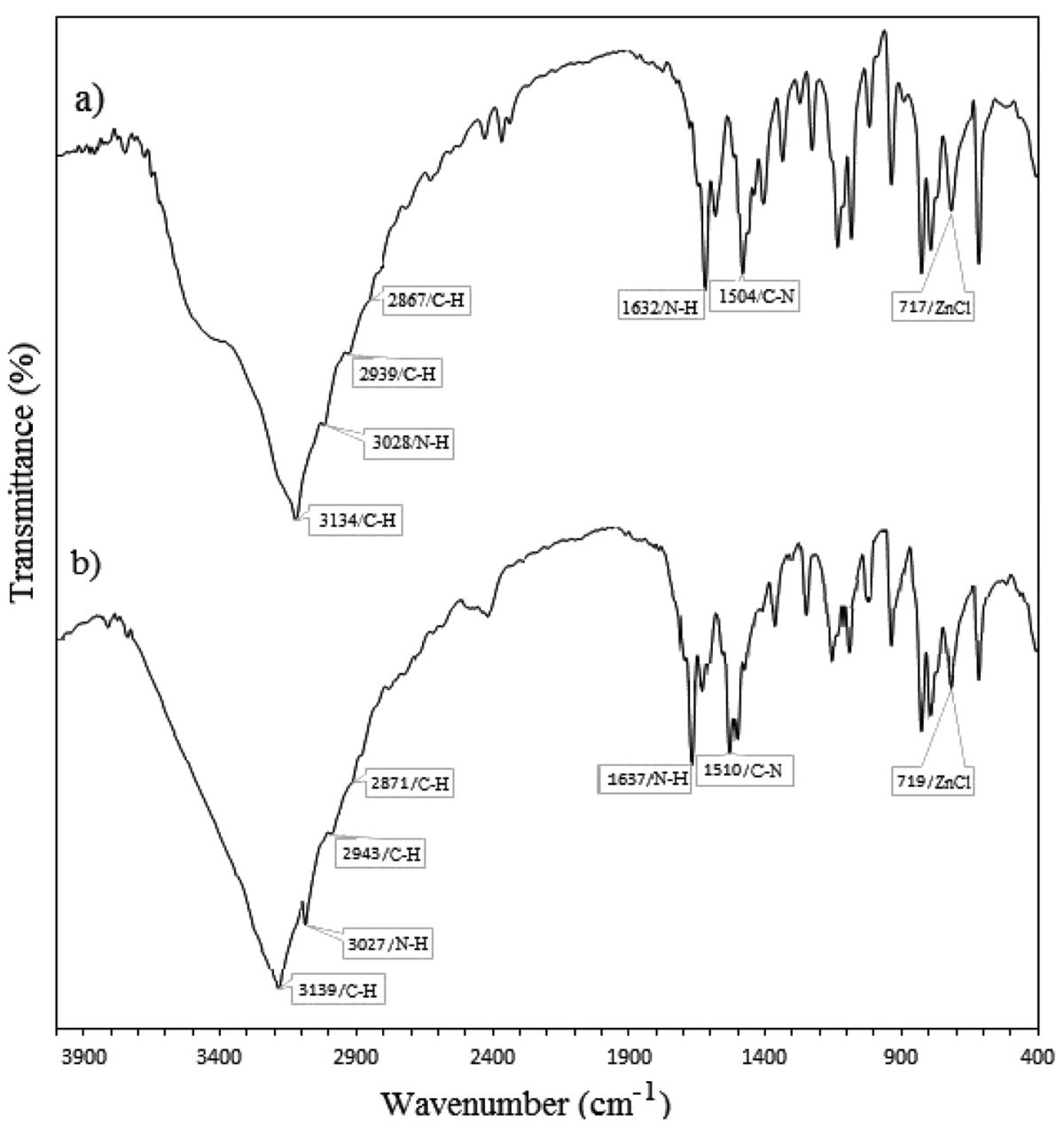

Fig. 12 FT-IR spectra of (a) fresh histaminium tetrachlorozincate and (b) the reused material after the $5^{\text {th }}$ run.

3.2.7 Synthesis of different chromeno[4,3-b]chromenes by histaminium tetrachlorozincate. The versatility of the current methodology was identified through the synthesis of a series of chromeno[4,3- $b]$ chromene derivatives using some aromatic aldehydes (Table 3). Aromatic aldehydes with different electron withdrawing/donating groups created the desired products in acceptable yields. However, in agreement with previous reports, aldehydes bearing electron withdrawing groups reacted a little better than those with electron donating groups.

3.2.8 Studying the stability and reusability of histaminium tetrachlorozincate. To study the stability and reusability of histaminium tetrachlorozincate, the catalyst was detached from the reaction mixture after completion of the first run via a simple filtration. Then, the filtered catalyst was washed with a copious amount of toluene and dried at room temperature before the next run. The catalyst was examined for five subsequent runs and good reusability was detected (Fig. 11). The yield efficiency decreased from $\sim 93 \%$ in the first run to $\sim 86 \%$ after the fifth run that indicates only a small deactivation. Moreover, comparison of the infrared spectra of fresh histaminium tetrachlorozincate with that of the regenerated one after the $5^{\text {th }}$ run proved the existence of principal characteristic bands around $1200-1800 \mathrm{~cm}^{-1}$, which clearly confirmed that the structure of histaminium tetrachlorozincate remained intact (Fig. 12). Typical experiments were repeated to confirm the reproducibility of the condensation reaction and the acquired yields were repeatable within $\pm 5 \%$ alteration.

3.2.9 Hot filtration test. A hot filtration experiment was also performed to prove that the catalytic activity of the photocatalyst originates from histaminium tetrachlorozincate in the reaction mixture and not from the leached or decomposed fragments. For this purpose, $2 \mathrm{mg}$ of histaminium tetrachlorozincate was added to a mixture of dimedone, 4-hydroxycoumarin and benzaldehyde in acetonitrile and the reaction was started for $1.5 \mathrm{~h}$. In this part, the product yield was $52 \%$. Then, toluene was added, the photocatalyst was separated and the reaction was continued for another $1.5 \mathrm{~h}$ with the filtrate. Yield\% was increased to only $57 \%$; therefore, no significant increase in yield\% proved the stability of the photocatalyst during the reaction progress. Clearly, this experiment confirmed that a $5 \%$ increase in yield $\%$ would be due to the leached or decomposed fragments from the mother active nanocomposite.

3.2.10 Suggesting a plausible reaction pathway. A feasible mechanism is disclosed for the generation of chromenes catalyzed by histaminium tetrachlorozincate, as shown in Fig. 13. ${ }^{47}$ 
<smiles>O=CBr</smiles>

(a)<smiles>O=c1oc2ccccc2cc1O</smiles>

(c)

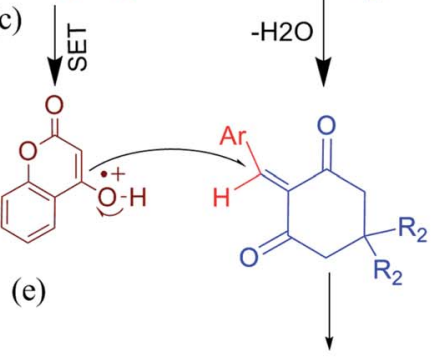

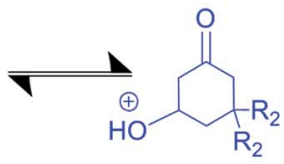

(b)

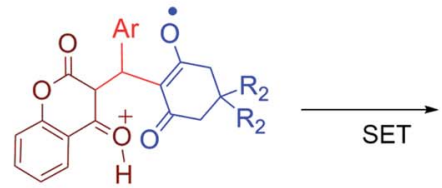

(f)

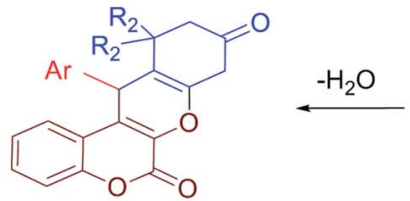

(i)
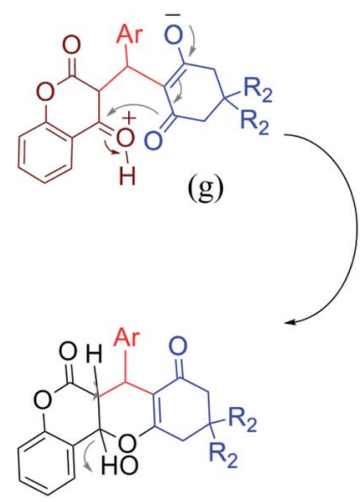

(h)

Fig. 13 A probable reaction pathway for the condensation reaction.

Formation of chromeno[ $4,3-b]$ chromene (i) occurs by condensation of the Knoevenagel product (d) attained from diketone and aromatic aldehyde. Thereafter, chromeno[4,3-b]chromene can be formed by the intra-molecular cyclization of the activated carbonyl group via elimination of a water molecule. 4-Hydroxycoumarin (c) is converted into a radical-cation (e) through a single electron transfer path. The radical-cation (e) undergoes a Michael type addition with $\beta$-dicarbonyl-enone (d) to furnish compound (f). Again at the same time, the intermediate (f) can be converted into $(\mathrm{g})$ by the mediation of the photocatalyst. Finally (h) undergoes a simple dehydration reaction and leads to the targeted molecule (i).

Finally, to demonstrate the applicability of the presented protocol, an experiment was planned on a gram scale under the optimized conditions (Scheme 2). Benzaldehyde (a) was reacted with dimedone (b) and 4-hydroxycoumarin (c) to give the desired chromeno[4,3- $b]$ chromene (d) in $\sim 85 \%$ under solvent free conditions in about $60 \mathrm{~min}$.<smiles>CC1(C)CC(=O)CC(C)(C)C1</smiles>

Scheme 2 Demonstration of the practicality of the presented protocol. 


\subsection{Spectral data of some synthesized chromenes}

3.3.1 10,10-Dimethyl-7-(4-nitrophenyl)-10,11-dihydrochromeno $[4,3-b]$ chromene- $6,8(7 \mathrm{H}, 9 \mathrm{H})$-dione (Table 3 , entry 1). Mp 208-210 ${ }^{\circ} \mathrm{C}$, FT-IR: 2932, 1718, 1650, 1605, 1528, 1459, 1342, 1177, 1098, 1031, 863, $761 \mathrm{~cm}^{-1}$. ${ }^{1} \mathrm{H}-\mathrm{NMR}(400 \mathrm{MHz}$, $\left.\mathrm{CDCl}_{3}\right): 1.10(\mathrm{~s}, 3 \mathrm{H}) ; 1.11(\mathrm{~s}, 3 \mathrm{H}) ; 2.17$ (d, $\left.J=16.3 \mathrm{~Hz}, 1 \mathrm{H}\right) ; 2.24$ $(\mathrm{d}, J=16.3 \mathrm{~Hz}, 1 \mathrm{H}) ; 2.66(\mathrm{~d}, J=18.2 \mathrm{~Hz}, 1 \mathrm{H}) ; 2.73(\mathrm{~d}, J=18.2 \mathrm{~Hz}$, $1 \mathrm{H}) ; 4.94$ (s, 1H); 6.91 (d, $J=8.8 \mathrm{~Hz}, 2 \mathrm{H}) ; 7.05$ (d, $J=8.8 \mathrm{~Hz}, 2 \mathrm{H})$; $7.32-7.42(\mathrm{~m}, 2 \mathrm{H}) ; 7.59(\mathrm{t}, J=8.3 \mathrm{~Hz}, 1 \mathrm{H}) ; 7.88(\mathrm{dd}, J=8.2 \mathrm{~Hz}, J$ $=1.5 \mathrm{~Hz} 1 \mathrm{H}) .{ }^{13} \mathrm{C}-\mathrm{NMR}\left(100 \mathrm{MHz}, \mathrm{CDCl}_{3}\right): 27.3,29.4,31.2,32.7$, $40.8,50.6,114.8,115.0,115.2,115.3,115.4,117.0,122.4,124.4$, $129.7,129.9,130.1,130.3,132.3,162.0,162.2,163.0,196.5$.

3.3.2 10,10-Dimethyl-7-phenyl-10,11-dihydrochromeno [4,3-b]chromene-6,8(7H,9H)-dione (Table 3, entry 2). Mp 220$222{ }^{\circ}$ C, FT-IR: 2961, 1711, 1663, 1604, 1492, 1452, 1362, 1324, 1289, 1182, 1165, 1051, 1032, 892, $765 \mathrm{~cm}^{-1}$. ${ }^{1} \mathrm{H}-\mathrm{NMR}(400 \mathrm{MHz}$, $\left.\mathrm{CDCl}_{3}\right): 1.08(\mathrm{~s}, 3 \mathrm{H}) ; 1.12(\mathrm{~s}, 3 \mathrm{H}) ; 2.22(\mathrm{~d}, J=16.3 \mathrm{~Hz}, 2 \mathrm{H}) ; 2.63$ $(\mathrm{d}, J=16.3 \mathrm{~Hz}, 2 \mathrm{H}) ; 4.98(\mathrm{~s}, 1 \mathrm{H}) ; 7.16(\mathrm{t}, J=7.3 \mathrm{~Hz}, 1 \mathrm{H}) ; 7.25(\mathrm{t}, J$ $=7.5 \mathrm{~Hz}, 2 \mathrm{H}) ; 7.29(\mathrm{~d}, J=7.7 \mathrm{~Hz}, 2 \mathrm{H}) ; 7.35-7.46(\mathrm{~m}, 2 \mathrm{H}) ; 7.63(\mathrm{t}$, $J=8.0 \mathrm{~Hz}, 1 \mathrm{H}) ; 7.85(\mathrm{dd}, J=8.0 \mathrm{~Hz}, J=1.9 \mathrm{~Hz}, 1 \mathrm{H}) .{ }^{13} \mathrm{C}-\mathrm{NMR}$ $\left(100 \mathrm{MHz}, \mathrm{CDCl}_{3}\right): 27.2,28.8,32.0,33.3,40.3,50.8,105.0,114.1$, $115.3,115.8,120.1,123.1,125.3,127.5,128.5,131.1,140.3$, 153.2, 153.7, 161.8, 196.2.

3.3.3 7-(4-Bromophenyl)-10,10-dimethyl-10,11-dihydrochromeno $[4,3-b]$ chromene-6,8 $(7 \mathrm{H}, 9 \mathrm{H})$-dione (Table 3 , entry 3). Mp 133-135 ${ }^{\circ} \mathrm{C}$, FT-IR: 3077, 2961, 2873, 1707, 1687, 1614, 1572, 1487, $1266 \mathrm{~cm}^{-1}$. ${ }^{1} \mathrm{H}-\mathrm{NMR}\left(400 \mathrm{MHz}, \mathrm{CDCl}_{3}\right): 1.21(2 \mathrm{H}$, $\left.\mathrm{CH}_{3}\right), 1.35\left(\mathrm{t}, 2 \mathrm{H}, \mathrm{CH}_{2}\right), 2.2\left(\mathrm{t}, 2 \mathrm{H}, \mathrm{CH}_{2}\right), 2.3(\mathrm{t}, 1 \mathrm{H}, \mathrm{CH}), 7.15-$ 7.21 (m, 4H, aromatic), 7.2-7.8 (m, 4H, aromatic). ${ }^{13} \mathrm{C}-\mathrm{NMR}(100$ $\left.\mathrm{MHz}, \mathrm{CDCl}_{3}\right)$ : 13.1, 19.5, 23.5, 58.4, 103.5, 104.9, 114.1, 118.7, $122.4,123.9,128.1,129.1,130.4,130.4,130.6,131.0,132.3$, 138.4, 144.1, 152.7, 162.8, 165.8, 204.9.

3.3.4 10,10-Dimethyl-7-(4-methoxyphenyl)-10,11-dihydrochromeno $[4,3-b]$ chromene-6,8 $(7 \mathrm{H}, 9 \mathrm{H})$-dione (Table 3, entry 4). Mp 187-189 ${ }^{\circ} \mathrm{C}$, FT-IR: 2957, 1726, 1661, 1607, 1508, 1455, 1359, 1301, 1252, 1183, 1168, 1140, 1034, 893, $765 \mathrm{~cm}^{-1} \cdot{ }^{1} \mathrm{H}-$ NMR (400 MHz, $\left.\mathrm{CDCl}_{3}\right): 1.14(\mathrm{~s}, 3 \mathrm{H}), 1.16(\mathrm{~s}, 3 \mathrm{H}), 2.22(\mathrm{~m}$, $2 \mathrm{H}), 2.35(\mathrm{~m}, 2 \mathrm{H}), 4.87$ (s, 1H), 7.25 (d, $J=7.6 \mathrm{~Hz}, 2 \mathrm{H}), 7.44$ (d, $J$ $=7.6 \mathrm{~Hz}, 2 \mathrm{H}), 7.56(\mathrm{~m}, 2 \mathrm{H}), 7.78(\mathrm{t}, J=8.0 \mathrm{~Hz}, 1 \mathrm{H}), 7.97(\mathrm{~d}, J=$ $8.0 \mathrm{~Hz}, 1 \mathrm{H}) .{ }^{13} \mathrm{C}-\mathrm{NMR}\left(100 \mathrm{MHz}, \mathrm{CDCl}_{3}\right): 27.0,27.1,28.4,30.2$, 37.0, 54.6, 106.3, 114.1, 114.1, 115.3, 123.0, 123.9, 128.3, 135.8, 136.2, 138.3, 143.9, 150.7, 153.1, 156.6, 158.1, 161.1, 195.9.

3.3.5 9,10-Dihydro-7-(3-nitrophenyl)-7H,11H-benzopyrano [3,2-c] chromene-6,8-dione (Table 3, entry 5). Mp 218-220 ${ }^{\circ} \mathrm{C}$ FTIR: 3100, 2935, 1734, 1525, $1364 \mathrm{~cm}^{-1}$. ${ }^{1} \mathrm{H}-\mathrm{NMR}(400 \mathrm{MHz}$, $\left.\mathrm{CDCl}_{3}\right): 2.07-2.22(\mathrm{~m}, 2 \mathrm{H}), 2.40-2.55(\mathrm{~m}, 2 \mathrm{H}), 2.77-2.86(\mathrm{~m}, 1 \mathrm{H})$, 2.92-2.98 (m, 1H), $5.08(\mathrm{~s}, 1 \mathrm{H}), 7.37(\mathrm{~d}, 1 \mathrm{H}), 7.42(\mathrm{t}, 1 \mathrm{H}), 7.46(\mathrm{t}$, $1 \mathrm{H}), 7.64(\mathrm{t}, 1 \mathrm{H}), 7.96(\mathrm{~m}, 2 \mathrm{H}), 8.05-8.07$ (m, 2H).

3.3.6 10,10-Dimethyl-7-(3-nitrophenyl)-10,11-dihydrochromeno $[4,3-b]$ chromene-6,8 $(7 \mathrm{H}, 9 \mathrm{H})$-dione (Table 3 , entry 6). Mp 230-232 ${ }^{\circ} \mathrm{C}$, FT-IR: 2973, 1718, 1657, 1608, 1526, 1352, 1182, 1142, 1094, 1034, 1032, 818, $765 \mathrm{~cm}^{-1} .{ }^{1} \mathrm{H}-\mathrm{NMR}(400 \mathrm{MHz}$, $\left.\mathrm{CDCl}_{3}\right): 1.11(\mathrm{~s}, 3 \mathrm{H}), 1.14(\mathrm{~s}, 3 \mathrm{H}), 2.24(\mathrm{~d}, J=15.6 \mathrm{~Hz}, 2 \mathrm{H}), 2.42$ $(\mathrm{d}, J=16.3 \mathrm{~Hz}, 2 \mathrm{H}), 4.97(\mathrm{~s}, 1 \mathrm{H}), 7.22(\mathrm{t}, J=7.6 \mathrm{~Hz}, 1 \mathrm{H}), 7.29(\mathrm{~d}, J$ $=7.5 \mathrm{~Hz}, 1 \mathrm{H}), 7.42(\mathrm{~d}, J=7.7 \mathrm{~Hz}, 2 \mathrm{H}), 7.62-7.68(\mathrm{~m}, 2 \mathrm{H}), 7.87(\mathrm{t}$, $J=7.9 \mathrm{~Hz}, 1 \mathrm{H}), 8.06(\mathrm{~d}, J=7.7 \mathrm{~Hz}, 1 \mathrm{H}) .{ }^{13} \mathrm{C}-\mathrm{NMR}(100 \mathrm{MHz}$,
$\left.\mathrm{CDCl}_{3}\right): 28.3,29.3,30.5,34.7,39.4,51.3,107.0,113.3,114.0$, $115.7,122.6,124.2$, 127.0, 128.2, 128.8, 130.9, 132.7, 136.4, $138.3,149.5,155.1,163.2,196.2$.

\section{Conclusions}

In conclusion, histaminium tetrachlorozincate is disclosed as an effective and recoverable photocatalyst in the synthesis of various chromeno $[4,3-b]$ chromenes to achieve high yields under solvent-less conditions at ambient temperature. This new photocatalyst is characterized by FT-IR, XRD, EDX, NMR, SEM and TEM. It is found that incorporation of histaminium ions into the framework of $\mathrm{ZnCl}_{4}{ }^{2-}$ significantly affected the photocatalytic activity of tetrachlorozincate and led to a recyclable nanomaterial. The major advantages of the presented methodology include easy and cheap preparation of the photocatalyst, simple work-up, nontoxic nature, broad substrate scope and complete atom economy under environmental friendly conditions in the presence of a simple green LED light. We believe that this protocol will play an important role in medicinal synthetic organic chemistry using a potent and economic alternative to the preparation of target materials. This protocol can be scaled up easily under mild conditions without needing to add further additives; thus, this photocatalyst can occupy a vital role among various introduced photocatalysts in organic synthesis.

\section{Conflicts of interest}

There are no conflicts to declare.

\section{Acknowledgements}

The work was supported by Hakim Sabzevari University.

\section{References}

1 D. Insuasty, J. Castillo, D. Becerra, H. Rojas and R. Abonia, Synthesis of Biologically Active Molecules through Multicomponent Reactions, Molecules, 2020, 25(3), 505.

2 C. G. Neochoritis, T. Zarganes-Tzitzikas, K. KatsampoxakiHodgetts and A. Dömling, Multicomponent Reactions, "Kinderleicht", J. Chem. Educ., 2020, 97(10), 3739-3745.

3 S. Zhi, X. Ma and W. Zhang, Consecutive multicomponent reactions for the synthesis of complex molecules, Org. Biomol. Chem., 2019, 17(33), 7632-7650.

4 C. S. Graebin, F. V. Ribeiro, K. R. Rogério and A. E. Kümmerle, Multicomponent Reactions for the Synthesis of Bioactive Compounds, A Review, Curr. Org. Syn., 2019, 16(6), 855-899.

5 B. König, Photocatalysis in Organic Synthesis-Past, Present, and Future, Eur. J. Org. Chem., 2017, 1979-1981.

6 R. Tayebee, E. Esmaeili, B. Maleki, A. Khoshniat, M. Chahkandi and N. Mollania, Photodegradation of methylene blue and some emerging pharmaceutical micropollutants with an aqueous suspension of WZnO- 
$\mathrm{NH}_{2} @ \mathrm{H}_{3} \mathrm{PW}_{12} \mathrm{O}_{40}$ nanocomposite, J. Mol. Liq., 2020, 317, 13928.

7 Q. Q. Zhou, Y. Q. Zou, L. Q. Lu and W. J. Xiao, Visible-light-induced organic photochemical reactions through energy-transfer pathways, Angew. Chem. Int. Ed, 2019, 58(6), 1586-1604.

8 B. Li, R. Tayebee, E. Esmaeili, M. S. Namaghi and B. Maleki, Selective photocatalytic oxidation of aromatic alcohols to aldehydes with air by magnetic $\mathrm{WO}_{3} \mathrm{ZnO} / \mathrm{Fe}_{3} \mathrm{O}_{4}$. In situ photochemical synthesis of 2-substituted benzimidazoles, RSC Adv., 2020, 10(67), 40725-40738.

9 S. Aguado, L. Casarrubios, C. R. de Arellano and M. A. Sierra, Revisiting the photochemical synthesis of [FeFe]hydrogenase mimics, reaction optimization, mechanistic study and electrochemical behaviour, RSC Adv., 2020, 10(50), 29855-29867.

10 M. Hricovíni, J. Asher and M. Hricovíni, Photochemical antisyn isomerization around the-N-N [double bond, length as m-dash] bond in heterocyclic imines, RSC Adv., 2020, 10(10), 5540-5550.

11 T. P. Yoon, Visible light photocatalysis, The development of photocatalytic radical ion cycloadditions, ACS Catal., 2013, 3(5), 895-902.

12 C. George, M. Ammann, B. D'Anna, D. J. Donaldson and S. A. Nizkorodov, Heterogeneous photochemistry in the atmosphere, Chem. Rev., 2015, 115(10), 4218-4258.

13 K. Zeitler, Photoredox Catalysis with Visible Light, Angew. Chem., Int. Ed., 2009, 48, 9785-9789.

14 X. Yumeng, Y. Hong and L. Aiwen, Synthetic applications of photoredox catalysis with visible light, Org. Biomol. Chem., 2013, 11, 2387-2403.

15 M. R. N. Jagan and R. J. S. Corey, Visible light photoredox catalysis applications in organic synthesis, Chem. Soc. Rev., 2011, 40, 102-113.

16 B. Swagata, C. P. Suresh, F. Polycarpos, E. O. Kevin, A. B. John and D. Dionysios, New Insights into the Mechanism of Visible Light Photocatalysis, J. Phys. Chem. Lett., 2014, 5, 2543-2554.

17 A. K. Sharma, J. Tiwari, D. Jaiswal, S. Singh, J. Singh and J. Singh, Organophotoredox catalysis, Visible-light-induced multicomponent synthesis of chromeno [4,3-b] chromene and hexahydro-1h-xanthene derivatives, Curr. Organocatal., 2019, 6, 222-230.

18 R. Tayebee, A. Pejhan, H. Ramshini, B. Maleki, N. Erfaninia, Z. Tabatabaie and E. Esmaeili, Equisetum arvense As an abundant source of silica nanoparticles. $\mathrm{SiO}_{2} / \mathrm{H}_{3} \mathrm{PW}_{12} \mathrm{O}_{40}$ nanohybrid material as an efficient and environmental benign catalyst in the synthesis of 2 -amino-4H-chromenes under solvent-free conditions, Appl. Organomet. Chem., 2018, 32(1), 3924.

$19 \mathrm{~F}$. Javadi and R. Tayebee, $\mathrm{TiO}_{2} /$ nanoclinoptilolite, a recyclable and high efficient heterogeneous nanocatalyst, for the synthesis of 2-amino-4H-chromene derivatives, Iran. J. Catal., 2017, 7(4), 283-292.

20 J. P. Gesson, N. Fonteneau, M. Mondon, S. Charbit, H. Ficheux and F. Schutze, Negma-Lerads, 7-carboxy- flavone derivatives preparation method and therapeutic use, US Pat., 6965039B2, 2005.

21 S. F. Razavi, M. Khoobi, H. Nadri, A. Sakhteman, A. Moradi, S. Emami, A. Foroumadi and A. Shafiee, Synthesis and evaluation of 4-substituted coumarins as novel acetylcholinesterase inhibitors, Eur. J. Med. Chem., 2013, 64, 252-259.

22 Z. Q. Xu, M. G. Hollingshead, S. Borgel, C. Elder, A. Khilevich and M. T. Flavin, In Vivo anti-HIV activity of (+)-calanolide a in the hollow fiber mouse model, Bioorg. Med. Chem. Lett., 1999, 9, 133-138.

23 C. Bruhlmann, F. Ooms, P. Carrupt, B. Testa, M. Catto, F. Leonetti, C. Altomare and A. Cartti, Coumarins Derivatives as Dual Inhibitors of Acetylcholinesterase and Monoamine Oxidase, J. Med. Chem., 2001, 44, 3195-3198.

24 M. Suzuki, K. Nakagawa-Goto, S. Nakamura, H. Tokuda, S. L. Morris-Natschke, M. Kozuka, H. Nishino and K. H. Lee, Cancerpreventive agents. Part 5. Anti-tumorpromoting effects of coumarins and related compounds on epstein-barr virus activation and two-stage mouse skin carcinogenesis, Pharm. Biol., 2006, 44, 178-182.

25 S. Emami, A. Foroumadi, M. A. Faramarzi and N. Samadi, Synthesis and antibacterial activity of quinolone-based compounds containing a coumarin moiety, Arch. Pharm., 2008, 341, 42-48.

26 J. Mori, M. Iwashima, M. Takeuchi and H. Saito, A synthetic study on antiviral and antioxidative chromene derivative, Chem. Pharm. Bull., 2006, 54, 391-396.

27 L. Firoozpour, N. Edraki, M. Nakhjiri, S. Emami, M. Safavi, S. K. Ardestani, M. Khoshneviszadeh, A. Shafiee and A. Foroumadi, Cytotoxic activity evaluation and QSAR study of chromene-based chalcones, Arch. Pharmacal Res., 2012, 35(12), 2117-2125.

28 K. N. Venugopala, V. Rashmi, B. Odhav and K. N. Venugopala, Review on natural coumarin lead compounds for their pharmacological activity, Biomed. Res. Int., 2013, e963248.

29 R. K. Nimesh, D. H. Dhaval, T. M. Prashant and K. P. Saurabh, Synthesis and evaluation of in vitro antitubercular activity and antimicrobial activity of some novel $4 \mathrm{H}$-chromeno[2,3-d]pyrimidine via 2-amino-4-phenyl4H-chromene-3-carbonitriles, Med. Chem. Res., 2011, 20, 854-864.

30 K. Nitin, K. Sushil, G. Himanshu and P. K. Sharma, 3Hydroxy-2-(substituted phenyl)-4H-chromen-4-one derivatives- synthesis, spectral characterization and pharmacological screening, WRJB, 2012, 1, 1-5.

31 K. Haider, S. Rahaman, M. S. Yar and A. Kamal, Tubulin inhibitors as novel anticancer agents, An overview on patents (2013-2018), Expert Opin. Ther. Pat., 2019, 29, 623641.

32 N. Thomas and S. M. Zachariah, Asian J. Pharm. Clin. Res., 2013, 6, 11-15.

33 M. K. Hussain, M. F. Khan, S. Khatoon, A. G. Al-Sehemi and M. Saquib, Chromenes, Phytomolecules with Immense Therapeutic Potential, InPlant-derived Bioactives, Springer, Singapore, 2020, pp. 185-204. 
34 V. Raj and J. Lee, $2 \mathrm{H} / 4 \mathrm{H}$-Chromenes-A Versatile Biologically Attractive Scaffold, Fron. Chem., 2020, 8, 623.

35 X. Yu, W. Lan, J. Li, H. Bai, Z. Qin and B. Fu, Enantioselective one-pot synthesis of $4 \mathrm{H}$-chromene derivatives catalyzed by a chiral Ni (ii) complex, RSC Adv., 2020, 10(72), 44437-44441.

36 M. P. Lati, F. Shirini, M. Alinia-Asli and M. A. Rezvani, $\mathrm{Fe}_{3} \mathrm{O}_{4} @ \mathrm{SiO}_{2}$-Sultone, A Novel and Recyclable Magnetic Nanocatalyst for the Efficient Synthesis of 3, 4 Dihydropyrano [c] Chromenes and 2-Amino-4H-Chromene Derivatives, J. Nanosci. Nanotechnol., 2020, 20(2), 973-982.

37 R. Chen, Z. Jalili and R. Tayebee, UV-visible light-induced photochemical synthesis of benzimidazoles by coomassie brilliant blue coated on $\mathrm{W}-\mathrm{ZnO} @ \mathrm{NH}_{2}$ nanoparticles, $R S C$ Adv., 2021, 11(27), 16359-16375.

38 B. Maleki, S. Babaee and R. Tayebee, Zn(L-proline) $)_{2}$ as a powerful and reusable organometallic catalyst for the very fast synthesis of 2-amino- $4 \mathrm{H}$-benzo [g] chromene derivatives under solvent-free conditions, Appl. Organomet. Chem., 2015, 29(6), 408-411.

39 N. Erfaninia, R. Tayebee, M. Dusek and M. M. Amini, Ethylene diamine grafted nanoporous UiO-66 as an efficient basic catalyst in the multi-component synthesis of 2-aminithiophenes, Appl. Organomet. Chem., 2018, 32(5), e4307.

40 R. Tayebee, A. F. Lee, L. Frattini and S. Rostami, $\mathrm{H}_{3} \mathrm{PW}_{12} \mathrm{O}_{40} /$ SBA-15 for the Solventless Synthesis of 3-Substituted Indoles, Catalysts, 2019, 9(5), 409.

41 R. Tayebee and M. Ghadamgahi, Solvent free one-pot multicomponent synthesis of 3, 4-dihydropyrimidin-2(1H)-ones catalyzed by mesoporous $\mathrm{NH}_{4} \mathrm{H}_{2} \mathrm{PO}_{4} / \mathrm{MCM}-41$ as an environmentally friendly, cheap, and effective catalyst, Arab. J. Chem., 2017, 10, S757-S764.

42 N. M. Ghohe, R. Tayebee and M. M. Amini, Synthesis and characterization of mesoporous NbZr/KIT-6 as a productive catalyst for the synthesis of benzylpyrazolyl coumarins, Mater. Chem. Phys., 2019, 223, 268-276.

43 J. A. Collado and F. J. Ramfrez, Infrared and Raman Spectra of Histamine-Nh4 and Histamine-Nd4 Monohydrochlorides, J. Raman Spectrosc., 1999, 30, 391-397.

44 R. B. Stephen, W. G. Constance and L. M. Sharon, Comparison of the Solid and Solution Conformations of Methapyriline, Tripelennamine, Diphenhydramine, Histamine, and Choline. The 'Infrared-X-Ray Method for Determination of Solution Conformations, J. Org. Chem., 1976, 41, 2283-2288.

45 M. B. Inoue, P. Oram, M. Inoue and Q. Fernando, Solution ${ }^{1} \mathrm{H}$ NMR and X-ray crystal structures of $\mathrm{Ca}^{2+}, \mathrm{Zn}^{2+}$ and $\mathrm{Cd}^{2+}$ complexes with 12- and 13-membered macrocycles, dioxotetraazacycloalkanediacetic acids, Inorg. Chim. Acta, 1996, 246, 401.

46 X. Zhong, W. T. Wu, H. N. Jie, W. Y. Tang, D. Y. Chen, T. Ruan and H. P. Bai, Degradation of norfloxacin by copper-doped $\mathrm{Bi}_{2} \mathrm{WO}_{6}$-induced sulfate radical-based visible light-Fenton reaction, $R S C$ Adv., 2020, 10, 38024.

47 A. K. Sharma, J. Tiwari, D. Jaiswal, S. Singh, J. Singh and J. Singh, Organophotoredox catalysis, Visible-light-induced multicomponent synthesis of chromeno $[4,3-b]$ chromene and hexahydro-1h-xanthene derivatives, Curr. Organocatal., 2019, 246, 222-230.

48 A. Saha, S. Payra and S. Banerjee, On water synthesis of pyran-chromenes via a multicomponent reactions catalyzed by fluorescent $\mathrm{t}^{-\mathrm{zrO}_{2}}$ nanoparticles, RSC Adv., 2015, 5, 101664-101671.

49 K. Pradhan, S. Paul and A. R. Das, Fe(DS $)_{3}$, an efficient Lewis acid-surfactant-combined catalyst(LASC) for the one pot synthesis of chromeno[4,3-b]chromene derivatives by assembling the basic building blocks, Tetrahedron Lett., 2013, 54, 3105-3110.

50 S. Vajar and M. Mokhtary, Nano-CuFe ${ }_{2} \mathrm{O}_{4} @ \mathrm{SO}_{3} \mathrm{H}$ catalyzed efficient one-pot cyclo-dehydration of dimedone and synthesis of chromeno [4,3- $b]$ chromenes, Polycyclic Aromat. Compd., 2019, 39, 111-123.

51 F. Khosravian, B. Karami and M. Farahi, Synthesis and characterization of molybdic acid immobilized on modified magnetic nanoparticles as a new and recyclable catalyst for the synthesis of chromeno $[4,3-b]$ chromenes, New J. Chem., 2017, 41, 11584-11590.

52 Z. Yin, M. Han, Z. Hu, L. Feng, Y. Liu, Z. Du and L. Zhang, Chem. Eng. J., 2020, 390, 124532.

53 S. Naraginti, Y. Li, Y. Wu, Ch. Zhang and A. Raj Upreti, Mechanistic study of visible light driven photocatalytic degradation of EDC $17 \alpha$-ethinyl estradiol and azo dye acid black-phytotoxicity assessment of Intermediates, RSC Adv., 2016, 6, 87246.

54 X. Zheng, J. Yuan, J. Shen, J. Liang, J. Che, B. Tang, G. He and H. Chen, J. Mater. Sci.: Mater. Electron., 2019, 30, 5986-5994.

55 R. K. Sharma, B. Arora, S. Sharma, S. Dutta, A. Sharma, S. Yadav and K. Solanki, Mater. Chem. Front., 2020, 4, 605620.

56 H. Emtiazi and M. A. Amrollahi, An Efficient and Rapid Access to the Synthesis of Tetrahydrochromeno[4,3-b] chromene-6,8-dione Derivatives by Magnesium Perchlorate, S. Afr. J. Chem., 2014, 67, 175-179.

57 Y. K. Al-Majedy, A. A. Al-Amiery, A. A. H. Kadhum and A. B. Mohamad, Efficient Catalyst One-Pot Synthesis of 7(Aryl)-10,10-dimethyl-10,11-dihydrochromeno[4,3-b] chromene-6,8(7H,9H)-dione Derivatives Complemented by Antibacterial Activity, BioMed. Res. Inter., 2016, 5891703.

58 R. Motamedi, S. Baghbani and F. F. Bamoharram, Catalytic Method for Synthesis of Benzopyrano[3,2-c]chromene-6,8dione Derivatives by Heteropoly Acids, Syn. Commun., 2012, 42(11), 1604-1612. 